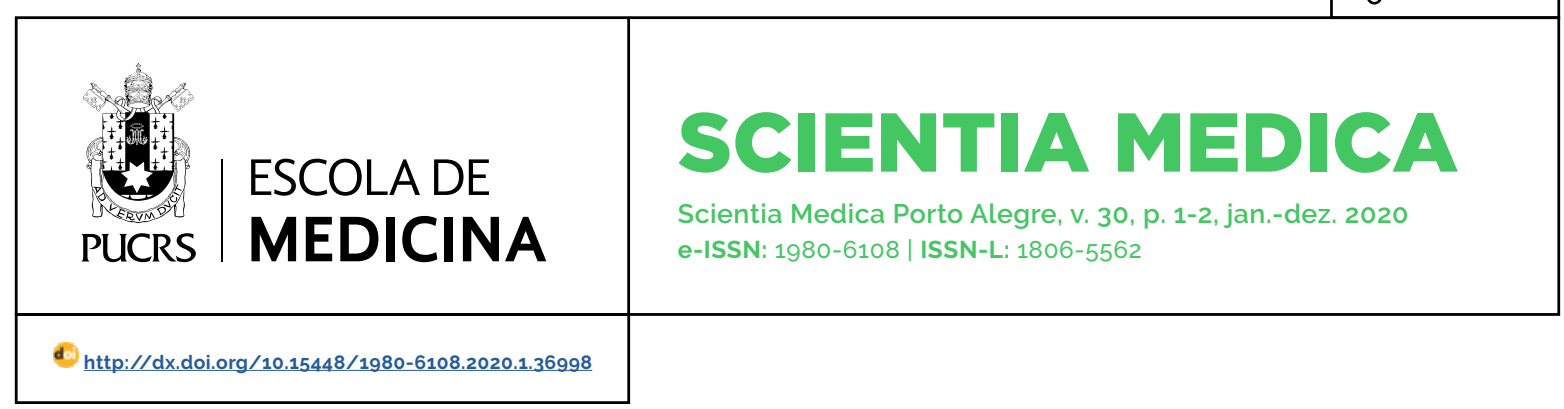

EDITORIAL

\title{
Publicação contínua em volume único
}

Continuous publication in single volume

\section{Manoel Antonio da Silva Ribeiro $^{1}$}

orcid.org/0000-0003-4883-6512 manoel.ribeiro@pucrs.br

Recebido em: 2 fev. 2020. Aprovado em: 3 fev. 2020. Publicado em: 21 dez. 2020.
Palavras-chave: editoração, publicações cientificas, fluxo contínuo

Desde o seu lançamento, em 1998, a Scientia Medica tem apresentado evoluções constantes em seu processo editorial. Há vários anos, o periódico subdivide sua publicação anual em quatro fascículos trimestrais (março, junho, setembro e dezembro de cada ano), porém com a publicação por artigo, uma vez cumpridas todas as exigências de revisão por pares, formatação e editoração. O ano de 2020 marcará uma nova etapa na sua história: um novo projeto gráfico, adequado à identidade visual da Pontifícia Universidade Católica do Rio Grande do Sul, e a migração da atual periodicidade de editoração para a publicação em fluxo contínuo, com número único no ano. Estratégias essas, que estão sendo adotadas nos processos editoriais de todos os periódicos da universidade, visando ao aumento na qualificação dos periódicos.

O processo de publicação em fluxo contínuo, também denominada publicação continuada (continuous publication, rolling pass e rolling publishing), é recomendado pela Associação Brasileira de Editores Científicos (1) e pela Scientific Electronic Library Online (SciELO) (2), e tem sido utilizado pela Scientia Medica desde 2015. É um método de editoração online que facilita os processos editoriais e de publicação, além de dar mais visibilidade aos artigos publicados. Conforme as orientações para publicações da SciELO (2, 3), essa modalidade promove rapidez no processo de comunicação e de disponibilização das pesquisas, com inúmeras vantagens para os usuários da informação científica: pesquisadores, estudantes, leitores, editores e agências de financiamento. Além disso, oferece várias vantagens operacionais como: 1) facilitar a indexação dos artigos nas bases de dados bibliográficas onde o periódico é indexado, com destaque para Google Scholar, PUbMED, SciELO, Scopus e Web of Science; 2) deixar de acumular os artigos já aprovados à espera da composição e diagramação do próximo número; e 3) manter a alimentação por seções e na estrutura (4). 
A utilização de um número único anual permitirá à Scientia Medica ter mais agilidade em suas publicações e evitará possiveis atrasos que poderiam ocorrer na sua editoração por fascículos. Portanto, em dezembro de 2019, a revista fechou o ciclo atual de publicação com o volume 29, número 4. A partir de 2020, suas publicações serão identificadas pelo volume seguido do número 1: 30(1) em 2020, 31(1) em 2021, 32(1) em 2022, e assim sucessivamente.

Os maiores desafios para a equipe editorial serão a adaptação para esse modelo dinâmico, a gestão completa do processo de publicações devido a um provável aumento de submissões, sem perder a qualidade das mesmas, e o cuidado em evitar endogenia excessiva. Espero que essas pequenas modificações, como desejado pela minha antecessora, Prof. . Dra. Eleonor Lago (5), "mantenham o constante crescimento deste importante veículo de comunicação, exemplo de qualidade, ética e integridade em publicação científica".

\section{Referências}

1. Barraviera B. As vantagens da publicação contínua de artigos... e os desafios a enfrentar. XXVI CEC Curso de Editoração Científica da Associação Brasileira de Editores Científicos [Internet]. São Paulo; 2019 lupdate 2019 Jun; cited 2020 Jan 30]. Available from: https://www.abecbrasil.org.br/eventos/xxvi_ curso/arquivos/quarta/benedito-quarta.pdf

2. SciELO. Guia para Publicação Contínua de artigos em periódicos indexados no SciELO [Internet]. São Paulo; 2018. [cited 2020 Jan 28]. Available from: http://old.scielo.org/local/Image/guiarpass.pdf

3. SCIELO. Critérios, politica e procedimentos para a admissão e a permanência de periódicos científicos na Coleção SciELO Brasil [Internet]. São Paulo; 2017. [cited 2020 Jan 30]. Available from: http://www. scielo.br/avaliacao/Criterios_SciELO_Brasil_versao_ revisada_atualizada_outubro_20171206.pdf.

4. Packer, A, Santos S, Sales DP, Salgado E. Acelerando a comunicação das pesquisas: as ações do SciELO [online]. SciELO em Perspectiva, 2016 [Cited 28 January 2020]. Available from: https://blog.scielo. org/blog/2016/03/10/acelerando-a-comunicacao-das-pesquisas-as-acoes-do-scielo/

5. Lago EG. Tempo de mudança - Editorial. Sci Med. 2019;29(1):e33561. https://doi.org/10.15448/1980$\underline{6108.2019 \cdot 1.33561}$

\section{Manoel Antonio da Silva Ribeiro}

Neonatologista, Doutor em Pediatria e Saúde da Criança pela PUCRS, Professor Adjunto da Escola de Medicina da Pontifícia Universidade Católica do Rio Grande do Sul (PUCRS, Porto Alegre, RS, Brasil); Editor da Scientia Medica, Porto Alegre, RS, Brasil.

\section{Endereço para correspondência}

Manoel Antonio da Silva Ribeiro

Pontificia Universidade Católica do Rio Grande do Sul Av. Ipiranga, 6681, Prédio 12A

Partenon, 90619-900

Porto Alegre, RS, Brasil 